rev.relac.int.estrateg.segur.7(1):211-240,2012

\title{
SEGURIDAD HEMISFÉRICA, ASISTENCIA Y DEMOCRACIA A INICIOS DE LA GUERRA FRÍA*
}

Silvina M. Romano*

\section{RESUMEN}

A la luz de estrategias de seguridad impulsadas por Estados Unidos, posteriores a la desarticulación de la Unión Soviética, como el Plan Colombia y la Iniciativa Mérida, y atendiendo a la creciente lucha por el acceso a materias primas y recursos naturales en la región, se propone analizar la política de seguridad hemisférica estadounidense a inicios de la guerra fría como una alternativa para ampliar el horizonte de comprensión de los procesos y lineamientos de seguridad actuales. Se planteará la articulación entre lo político, lo económico y lo militar, considerando la relación, objetivos y alcances de la seguridad, el desarrollo y la democracia, según las concepciones y líneas de acción planteadas por funcionarios estadounidenses en documentos públicos, como el Boletín Oficial del Departamento de Estado estadounidense y material "secreto" (hoy desclasificado) del mismo Departamento.

Palabras clave: Estados Unidos, América Latina, seguridad, desarrollo, democracia

* Este artículo es parte de la investigación titulada "La guerra fría y la política exterior estadounidense hacia América Latina: seguridad, democracia y desarrollo (1947-1963)", financiada por CONICET (20102011) y desarrollada en el CIECS, UNC, Córdoba, Argentina.

** Doctora en Ciencia Política por el Centro de Estudios Avanzados de la Universidad Nacional de Córdoba Argentina, becaria posdoctoral del CONICET-CIECS, Córdoba, Argentina. silvinamceleste@gmail.com 


\title{
HEMISPHERIC SECURITY, ASSISTANCE AND DEMOCRACY AT THE START OF THE COLD WAR
}

\begin{abstract}
In light of the security strategies prompted by the United States after the break-up of the Soviet Union, like Plan Colombia and the Merida Initiative, and considering the growing struggles for access to raw materials and natural resources in Latin America, this article aims to analyze the American hemispheric security policy at the start of the cold war, as an option to broaden the horizon of understanding of the current processes and security guidelines. The links between political, economic and military aspects will be discussed, considering the relation, objectives and reaches of security, development and democracy, from the viewpoint and guidelines proposed by U.S. officials in public documents, such as the State Department Official Bulletin and other "secret" material (now declassified) by the State Department.
\end{abstract}

Key Words: United States, Latin America, security, development, democracy

\section{SEGURANÇA HEMISFÉRICA, ASSISTÊNCIA E DEMOCRACIA NO COMEÇO DA GUERRA FRIA}

\section{RESUMO}

À luz das estratégias de segurança promovidas pelos Estados Unidos, após a dissolução da União Soviética, como o Plano Colômbia e a Iniciativa Mérida, e visando a luta crescente pelo acesso às matérias-primas e aos recursos naturais na região, propõe-se analisar a política de segurança hemisférica americana no começo da Guerra Fria como uma alternativa para ampliar o horizonte de compreensão dos processos e das diretrizes de segurança que estão em vigor. Serão esboçados os vínculos entre o político, econômico e militar, considerando a relação, objetivos, âmbito da segurança, o desenvolvimento e a democracia, de acordo com os conceitos e linhas de ação propostas pelos funcionários americanos em documentos públicos como o Diário Oficial do Departamento de Estado dos Estados Unidos e o material "secreto" (agora desprestigiado) deste departamento.

Palavras chave: Estados Unidos, América latina, segurança, desenvolvimento, democracia. 


\section{INTRODUCCIÓN}

A la vista de las "amenazas para la seguridad" surgidas o reforzadas en América Latina a partir de la desarticulación de la Unión Soviética, como la "inestabilidad" (Loveman, 2006), el narcotráfico, el terrorismo, el "narcoterrorismo", la "narcoinsurgencia", el crimen organizado, la inseguridad ciudadana, etc., se han lanzado programas de seguridad regional de modo conjunto entre gobiernos latinoamericanos y el estadounidense, como el Plan Colombia, la Iniciativa Regional Andina y la Iniciativa Mérida, desplegados en Colombia y la zona andina, en México y en expansión hacia América Central. Estos programas han incrementado la presencia de las fuerzas armadas en el control del orden interno en conjunto con las fuerzas policiales, han disparado los gastos en "defensa" por parte de los Estados implicados, además de crecer las tensiones en zonas fronterizas (caso clave la relación de Colombia con sus vecinos, Venezuela y Ecuador, la frontera México-Estados Unidos y Guatemala-México). Todo esto, en un contexto de aumento de la pobreza y la desigualdad, la profundización de mecanismos de acumulación característicos de economías extractivistas y primario-exportadoras (Delgado y Romano, 2011). A esto se suma el rechazo al proyecto de integración liderado por Estados Unidos, el Área de Libre Comercio para las Américas (ALCA), el impulso de procesos de integración regional no centrados en la liberalización del mercado, como la Alternativa Bolivariana para las Américas, así como la creación de la Unión de Naciones Suramericanas (acuerdo de integración política y para la seguridad) y la Comunidad de Estados Latinoamericanos y Caribeños (CELAC), organismos interamericanos que excluyen a Estados Unidos y Canadá.

De este modo, si bien se han producido importantes cambios desde fines de los 80 hasta la actualidad, parece necesario señalar que tales cambios no han impedido la permanencia de significativas continuidades respecto de los lineamientos y prácticas que caracterizaron la política de seguridad hemisférica de Estados Unidos durante la guerra fría, vinculada ahora a otras amenazas, de modo que el "enemigo común" se recicla, quebrando la ilusión de que "Tal vez con el fin de la guerra fría, la bandera anticomunista en cuyo nombre se han perpetrado tantos crímenes y se han maleado tantas mentes, deje de estar enarbolada" (Gleijeses en Cullather, 2006: 173).

Considerando este panorama en el que se articula lo económico, lo político y lo militar en los lineamientos para la seguridad hemisférica, resulta interesante volver a pensar las relaciones de Estados Unidos con América Latina en la primera década de la guerra fría, que parece haber quedado en un pasado lejano que poco tiene para decir en la actualidad. Así, resurgen algunas preguntas vinculadas a las concepciones y prácticas del gobierno estadounidense hacia la región en dicho período: ipor qué la seguridad?, ¿seguridad para qué o para quiénes?, ¿cuál era el rol de América Latina según esta concepción?, ¿por qué y para qué se planteó la complementación de la seguridad hemisférica con la seguridad interna?, ¿cuáles eran los objetivos de la asistencia militar?, ¿por qué se articuló con la asistencia "técnica" para el desarrollo?, ¿̇en qué medida el 
"desarrollo" y la "democracia" se vincularon a las concepciones y lineamientos de seguridad hemisférica e interna?

Para abordar esta problemática, se recurrirá a documentos del Departamento de Estado, que contienen información "clasificada", así como a la información oficial publicada por el Boletín Oficial del Departamento de Estado. Se entiende que sigue siendo fundamental estudiar los documentos elaborados por funcionarios estadounidenses, en tanto su relectura desde diferentes contextos históricos y subjetivos permite diferentes interpretaciones. Como parte de este retorno a los documentos, también se propone recuperar los aportes del neomarxismo, el imperialismo norteamericano y la teoría de la dependencia, que no son las corrientes predominantes en los análisis sobre las primeras décadas de guerra fría ${ }^{1}$, al menos en la disciplina de las relaciones internacionales, donde todavía posee una fuerte impronta la visión realista, si bien cada vez adquieren mayor protagonismo nuevas corrientes como el constructivismo (Salomón, 2001).

Conviene apuntar aquí brevemente algunas de las corrientes teóricas más relevantes sobre la guerra fría, para luego argumentar la razón por la cual el trabajo se basa en la perspectiva crítica. Las posturas teóricas clásicas sobre la guerra fría se encarnaron en dos corrientes de pensamiento antagónicas. Una de ellas, la escuela de la amenaza soviética (también llamada escuela "ortodoxa"), representada por perspectivas como la de John L. Gaddis (1972), sostenía que el origen de la guerra fría se hallaba en el expansionismo soviético. Esta corriente estaba estrechamente vinculada a los estudios de los funcionarios norteamericanos que consideraban que la guerra fría era resultado del expansionismo estalinista de naturaleza paranoica, tal como lo expone Arthur Schlesinger (1990), al advertir que la contienda Oeste-Este se debía a la paranoia de Stalin, a que los soviéticos no habían aceptado el Plan Marshall y a que se guiaban por el principio de las esferas de influencia. Como postura opuesta a dichos puntos de vista, se encuentran las investigaciones sustentadas en la hipótesis del imperialismo norteamericano, que postulan que el expansionismo y el militarismo son intrínsecos al capitalismo norteamericano (William Appelman Williams, 1960; Walter Lafeber, 1989; Paul Sweezy y Harry Magdoff, 1972). Estos estudios se asocian al revisionismo de izquierda, el cual sostiene que los instintos económicos norteamericanos, sumados a la ideología capitalista liberal, eran los responsables principales del enfrentamiento Este-Oeste, siendo el trabajo de Gabriel Kolko (1968) uno de los más influyentes (Pozzi, 2003: 14-15, 20).

Frente a tales argumentos, se plantearon las tesis "posrevisionistas", encabezadas por nuevos aportes de Gaddis (1989), que sostenían que la actuación de ambos bloques había generado reacciones hostiles en el otro bando y esto condujo a una espiral de acción-reacción en el cual

1. Ver: Williams, 1960; Kolko, 1968; LaFeber, 1989; Chomsky, 2003; Sweezy (1973) Baran y Sweezy (1974), Huberman y Sweezy (1973), Sweezy y Magdoff (1972), Dos Santos (1972, 1975), Sunkel (1975); Cotler y Fagen (1972); Fernandes (2008), Gunder Frank (1970), Johnson (1970); Cardoso y Faletto (1973); Saxe Fernandez (1975). 
la tensión a veces pareció llevar al borde de una guerra nuclear que no era deseada ni por los Estados Unidos, ni por la Unión Soviética. Una de las causas de este accionar eran los múltiples malentendidos y las disputas burocráticas al interior de cada potencia (Gaddis, 1989:364-370). A su vez, desde esta postura se entiende que los funcionarios estadounidenses no tenían por objetivo la supremacía económica de Estados Unidos (Joseph, 2004: 72). En algunos aportes más recientes, John L. Gaddis $(1994,2003)$ parece retomar en buena medida la ortodoxia prerevisionista, al centrar las responsabilidades de la guerra fría en el accionar de la Unión Soviética.

Por otra parte, se encuentran los aportes desarrollados con posterioridad a la caída del comunismo soviético y la apertura de los archivos de la Unión Soviética (1991), como el de Melvin Leffler (1999: 511, 522), que expone que a diferencia de lo sostenido por el gobierno norteamericano, la Unión Soviética no tenía demasiadas intenciones de expandirse y en cambio se inclinaba más hacia una estrategia defensiva y prudente, con lo cual quedan en duda las intenciones expansionistas soviéticas que constituían la principal amenaza, según las lecturas del gobierno estadounidense. Además, plantea que es necesario tener en cuenta la presencia de las creencias y la ideología para analizar el desarrollo de la guerra fría, analizando cómo se relacionan aquellas con los intereses, las estrategias, el poder y la geopolítica. También a partir de la desclasificación de los documentos soviéticos, desde algunas corrientes europeas, se postuló la premisa -reforzando lo expuesto por la postura revisionista- de que si bien de hecho el expansionismo de Estados Unidos fue más notable que el de la Unión Soviética, el patrón era que Estados Unidos "era invitado" por los demás países a intervenir en el marco de la guerra fría, es decir, se trataba de un "imperialismo por invitación" (Blanton en Joseph 2008: 48).

En este escrito, el punto de partida es la perspectiva crítica (los aportes del neomarxismo, el revisionismo, el imperialismo y la teoría de la dependencia), pues a nivel epistemológico, estas corrientes plantean la necesidad de cuestionar el orden dado. Según teóricos de las relaciones internacionales, el marxismo busca exponer las verdades ocultas o subyacentes a los eventos que ocurren en la política internacional (guerras, tratados internacionales, asistencia, etc.) que se llevan a cabo en el marco de estructuras que tienen una enorme influencia en estos acontecimientos, las estructuras del sistema capitalista global (Hobden y Jones, 2001). Así, para el caso de la guerra fría, no basta con enunciar que muchas de las acciones y decisiones se debieron a malentendidos y disputas burocráticas, sino que interesa indagar en los intereses subyacentes a tales decisiones y las herramientas para legitimar ese "estado de cosas", es decir, la estructura vigente.

Cox (1981) plantea el concepto de "estructuras históricas", que implica una combinación particular de patrones de pensamiento, condiciones materiales e instituciones humanas que mantienen una coherencia entre ellas. Estas estructuras no determinan mecánicamente la acción de las personas pero sí devienen en el contexto en el cual las acciones hallan determinadas presiones, 
hábitos, expectativas y restricciones (Cox, 1981: 135). Son estas estructuras las que ayudan a comprender los acontecimientos como parte de procesos y no como "sucesos" aislados en el tiempo y el espacio.

El avance hacia un conocimiento crítico implica reconocer que "la ilusión objetivista" de las ciencias, se contradicen con la posibilidad de un conocimiento vinculado a la praxis y orientado a la emancipación (Habermas, 1986)². Este proceso exige el desvelamiento y el desocultamiento de las huellas de lo no dicho, o de aquellos discursos que fueron reprimidos o invisibilizados en virtud de la visibilidad de otros que adquirieron el status de "verdaderos" y legítimos (Habermas, 1986).

Siguiendo lo anterior, se considera válido volver a la guerra fría (aunque sea uno de los períodos más estudiados) para cuestionar y profundizar en las estrategias de expansión del sistema capitalista hacia la periferia (en tanto estructura histórica) y los mecanismos de legitimación implementados para "naturalizar" dicho proceso. Esto implica la tarea mínima de articular lo político, lo económico y lo militar. Asimismo, esto lleva a preguntarse sobre el modo en que se han generalizado y consagrado ciertos "cortes históricos", que en muchos casos han sido utilizados para desvincular totalmente el pasado del presente, no sin obedecer a determinados intereses.

\section{ESTADOS UNIDOS Y LOS LINEAMIENTOS PARA LA SEGURIDAD HEMISFÉRICA}

Al abordar la guerra fría, indudablemente se está haciendo referencia a uno de los temas más estudiados desde la disciplina de las relaciones internacionales, que es en efecto el tema con el que se consolidó esta disciplina después de la Segunda Guerra Mundial ${ }^{3}$. Acudiendo a una

2. Para dar sólo un ejemplo, diremos que la "perspectiva histórica" implica según los parámetros de Carr (1961: 95, 121), la capacidad de "priorizar causas" en orden a la relevancia de las mismas. El modo de aproximarse a los acontecimientos se lleva a cabo, en primer lugar, a través de la recopilación de datos primarios (las fuentes), para proceder luego a la interpretación, procesos en los cuales el investigador "interviene irrevocablemente". Retomando tales reflexiones, es claro que se le otorga una importancia fundamental a la selección de ciertos documentos (y acontecimientos) y el descarte de otros. Precisamente, Walsh (1974: 117) sostiene que el proceso de selección constituye la médula del conocimiento histórico porque, por un lado, el historiador sólo puede abarcar una porción de la realidad y concentrar su atención en "un conjunto limitado de aspectos del pasado"; por otro lado, ningún investigador puede narrar "todo" lo sucedido en el pasado, aún dentro del campo de estudio que haya elegido, destacando algunos hechos e ignorando otros por completo.

3. Hay un consenso acerca de que, si bien hubo organismos y cátedras vinculados a las Relaciones Internacionales desde inicios de siglo XX en Estados Unidos y el Reino Unido, además de la creación de la Sociedad de las Naciones (del Arenal, 1994), es con la guerra fría que se sistematizan los estudios sobre relaciones internacionales como campo disciplinar. Es en este período que asciende el realismo como teoría hegemónica de las relaciones internacionales, como crítica a la perspectiva idealista-liberal que había predominado en el período entre guerras. Por ultimo, es desde Estados Unidos que se lidera la consolidación de esta disciplina y la validez del realismo como teoría legitimadora del conflicto bipolar (Hoffman, 1991). El concepto principal del realismo es "la razón de Estado" 
concepción amplia de guerra fría, se entiende que fue el producto de la confrontación entre dos sistemas socioeconómicos contradictorios y antagónicos: capitalismo versus comunismo y que se caracterizó por una lucha a nivel diplomático, político, ideológico, militar y económico. Sus causas tenían que ver tanto con el desarrollo del mundo de la posguerra, como con el creciente poderío de las potencias implicadas y con una compleja situación interna tanto en la Unión Soviética como en Estados Unidos. A nivel interno, los Estados Unidos contaban con importantes conflictos en el sector laboral, conflictos económicos debido a la desmovilización de posguerra y con una desalentadora escasez de "clientes" en el mercado internacional. Para resolver estos inconvenientes, el gobierno estadounidense aplicó políticas por separado que se articularon gracias al comienzo de la guerra fría. Para el conflicto laboral, implementó leyes que permitieron mayor control y represión por parte del Estado; para mantener el crecimiento económico se impulsó un creciente complejo militar-industrial, y para regenerar los mercados en el exterior, la administración Truman lanzó el Plan Marshall (European Recovery Program) ${ }^{4}$ con el objetivo de reconstruir a Europa. Con respecto a la Unión Soviética, puede decirse que contaba con importantes condicionamientos a nivel económico y en términos de seguridad, en comparación con la situación de los Estados Unidos, por lo que se estima que no estaban dispuestos a dejar de lado tan fácilmente los acuerdos internacionales (Pozzi, 2003: 14-19)

¿Para qué servía esta nueva guerra? ¿Cuál era el pilar sobre el cual se erigía la nueva estructura estatal de seguridad? La base era el complejo industrial-militar como eje de la expansión del capitalismo monopólico de posguerra. Se sabe que la economía estadounidense no se recuperó de la crisis del 30 por las medidas del gobierno de Roosevelt, sino gracias a la economía de guerra (Hobsbawm, 1999; Adams, 1976). Para sostener esta economía se generó una estrecha relación entre las empresas de armamentos y el Pentágono (Melman, 1972), lo que se tradujo en una creciente influencia de los mandos militares en la toma de decisión a nivel gubernamental (Mills, 1978; Melman, 1972: 18). ${ }^{5}$

que implica que el Estado es el actor principal de la política internacional; que el líder debe buscar poder; que se deben calcular racionalmente los costos para la supervivencia del Estado. A diferencia del liberalismo, el realismo sostiene que no existen principios universales y, quizás lo más interesante, es que la razón de Estado tiene una "doble moral": un estándar para los ciudadanos al interior de la frontera y un estándar para la política internacional, porque los asuntos internacionales obligan a los líderes a actuar en el exterior con acciones que pueden ser inaceptables para los ciudadanos de el propio Estado (por ejemplo: matar, mentir, engañar) (Dunne y Schmidt, 2001: 141161). Ver: Barbé (1995), Salomón (2001).

4. Este Paln fue elaborado por el Grupo de Planificación de Políticas (Policy Planning Staff, PPS) del Departamento de Estado, liderado en ese momento por George Kennan.

5. Esta tendencia era legitimada desde la academia, junto con las posturas realistas. Un ejemplo de esta legitimación, son las ideas de Huntington: "Lo que se requiere de los líderes militares es un esfuerzo más para dar forma a un nuevo orden político. En muchas sociedades, la última posibilidad real de una institucionalización política que no caiga en el camino totalitario puede ser la oportunidad que tienen los militares para mostrarse políticamente creativos. Si los militares fracasan en aprovechar esa oportunidad, el incremento de la participación (popular) transformará a la sociedad en un sistema pretoriano de masas. En tal sistema la oportunidad para crear instituciones política pasa desde los militares, apóstoles del orden, a manos de esos otros líderes de la clase media, que son los apóstoles de la revolución" (Huntington en Tapia y Valdés, 1980: 70). 
Este complejo garantizaba el crecimiento y expansión de la economía estadounidense: "En los tres primeros trimestres de 1969, aproximadamente 8.3 millones de personas tenían empleo como consecuencia del programa militar: 3.5 millones en las fuerzas armadas, 1.3 millones de empleados civiles del Departamento de Defensa y 3.5 millones participando en la producción y el transporte de artículos adquiridos por las fuerzas militares...".

Además de mantener elevado el nivel de mano de obra ocupada, la fabricación de equipos y armamentos mantenía alta la producción. Si estos equipos eran considerados como bienes durables en conjunto con los bienes producidos por otras empresas privadas, se deriva de allí que el gobierno norteamericano, en 1963, adquiría directa o indirectamente el 36\% de esta producción (Sweezy y Magdoff, 1972: 72).

La expansión del capital y los productos estadounidenses hacia la periferia estaba ampliamente respaldada por el Estado a través de un sistema legal (por ejemplo, la Ley de Seguridad Mutua, 1952); una serie de acuerdos de seguridad a nivel interamericano e internacional (como el TIAR, 1947 y la OTAN, 1949); la creación de organismos financieros y económicos internacionales como el BIRF (hoy Grupo Banco Mundial) y el FMI, instituciones creadas para hacer operativo lo acordado en la conferencia de Bretton Woods (liberalización de los mercados y el dólar como divisa). Pero la mejor garantía para la expansión económica era el arsenal militar en permanente crecimiento. Como sostiene Wills (2010: 9)

"El mito del capitalismo es que el libre mercado es el sistema económico más eficiente. Pero no lo es. Fue la guerra y no el 'Nuevo Trato', lo que ayudó a salir de la Gran Depresión. En tiempos de guerra, el gobierno puede impulsar la producción de materias primas, canalizar la investigación, subsidiar nuevos métodos de producción, sin tener que tomarse el tiempo de ver si son rentables, redistribuir la mano de obra, eliminar de la competencia a los ineficientes (...) La guerra, que desde una lógica superficial destruye tantos bienes, es generalmente buena para la economía...".

La "militarización de la política" a nivel interno se tradujo en la política exterior estadounidense, que fue definida como política de "contención" primero, de "represalia masiva" después y luego, como "guerra limitada" en la periferia (Barnet, 1974: 6).

Una de las concepciones de seguridad que se manejaban desde el gobierno de Estados Unidos para fines de la década de 1940 planteaba el estrecho vínculo entre el bienestar de este país y la paz y la seguridad en la comunidad mundial, pues "una agresión en cualquier lado, puede amenazar la seguridad de Estados Unidos" USDS, FR, 1949, Vol I,. 270) ${ }^{6}$. Esta definición de

6. Lo abreviado se corresponde con United States Department of State, Foreign Relations. 
seguridad nacional se combinaba con los objetivos de Estados Unidos para enfrentar la "guerra global", que muestran el rol de líder asumido por este país, y su "deber" de "asegurar la integridad del Hemisferio Occidental y promover y desarrollar su capacidad para iniciar la guerra (...), apoyar el esfuerzo de guerra de nuestros aliados por medio de la provisión de la asistencia militar que sea posible" (USDS, FR, 1950, Vol I, 603).

Estas premisas de la seguridad hemisférica fueron aceptadas y ratificadas por los países de América Latina que firmaron el Tratado Interamericano de Asistencia Recíproca (1947). Este acuerdo de seguridad colectiva establece una noción de Seguridad Hemisférica tan amplia como ambigua, al ser identificada con cualquier agresión armada o no, intra o extra continental. Así, la amenaza podría provenir de "una agresión que no sea ataque armado, o por un conflicto extra continental o intracontinental, o por cualquier otro hecho o situación que pueda poner en peligro la paz de América" (TIAR, 1947, art. 6, subrayado propio).

Esta concepción de la "defensa colectiva" es remarcada en los comunicados al interior del gobierno estadounidense:

"el concepto de defensa hemisférica está basado en un enfoque regional, más que en un enfoque país por país. Por ejemplo, los problemas de seguridad de las vías de comunicación marítima están divididos en las áreas del Atlántico del Sur, Pacífico del Sur, Caribe y del Occidente Mexicano, y deben ser responsabilidad conjunta de las naciones cercanas a esas áreas. Lo mismo, si bien la seguridad de la fuente de estaño corresponde a Bolivia, el tránsito de éste hasta Estados Unidos es responsabilidad compartida por al menos media docena de Estados." (USDS, FR, 1950, Vol I, 634).

En ese marco, el rol geopolítico y geoeconómico ${ }^{7}$ de América Latina se definía de acuerdo con las metas planteadas en la estrategia militar de Estados Unidos para la región, que debían estar orientadas a garantizar:

“a) la continua y creciente producción y entrega de materiales estratégicos esenciales; b) si bien debe mantenerse un amplio espectro para el cambio político normal, el mantenimiento al interior de cada nación de la estabilidad política y la seguridad interna para garantizar la protección de instalaciones de las cuales

7. La geopolítica y la geoeconomía, inseparablemente tejidas (dada la íntima relación del hombre con la naturaleza al transformarla y transformarse en el proceso de trabajo), aluden a la forma como el capitalismo está pensando el espacio para que sea funcional de acuerdo con una lógica propia y con sus distintas estructuras nacionalistas de poder, donde estas últimas se juegan la hegemonía mundial. Es decir, son los términos específicos en y con los que el Estado capitalista refleja su concepción del espacio y que por lo tanto él mismo inaugura, sin que lo anterior signifique que el Estado precapitalista no lo haya tenido desde su peculiar lógica histórica determinada (Delgado Ramos, 2002: 26). 
dependen la producción y entrega de materiales estratégicos; c) la cooperación mutua de todas las naciones de América Latina en apoyo de Estados Unidos; d) la protección de vías de comunicación vitales; e) la provisión, desarrollo, operación y protección de aquellas bases que puedan ser requeridas para el uso de Estados Unidos y para la protección de vías de comunicación; f) la protección coordinada de invasiones y redadas..." (USDS, FR, 1950, Vol I,. 633, subrayado propio).

El párrafo anterior da cuenta del objetivo principal de las seguridad, que se repite en la mayoría de los comunicados clasificados: garantizar el flujo de materias primas y materiales estratégicos de América Latina hacia Estados Unidos, para lo cual era necesaria la seguridad hemisférica, pero también la "estabilidad" y seguridad internas. En este esquema, las fuerzas armadas de otras repúblicas americanas adquirían un rol fundamental, que sería apoyado por Estados Unidos, que procuraría: mantener las misiones de entrenamiento en América Latina, entrenar a nacionales de América Latina en territorio estadounidense, realizar planes conjuntos para la defensa del hemisferio, llevar a cabo la transferencia de equipo militar (USDS, FR, 1950, Vol I,,639-640).

En el marco de esta (re)definición de la seguridad hemisférica en la guerra fría, una de las cuestiones discutidas entre el Departamento de Estado, el Departamento de Defensa y el Consejo de Seguridad Nacional fue lo relativo a cómo debía implementarse la ayuda militar de Estados Unidos a América Latina en el marco del TIAR. No era tarea fácil justificar la asistencia militar mientras se predicaba que las grandes diferencias entre Occidente y el mundo comunista, eran la libertad y la democracia (Romano, 2010).

Es importante señalar algunos antecedentes. En julio de 1945, Truman apoyó los lineamientos orientados al "entrenamiento y equipamiento de las fuerzas armadas de otras repúblicas americanas", donde establecía que, en vistas de la escasa preparación que habían demostrado en el terreno militar las naciones de América Latina, Estados Unidos debía, en lo posible: "a) Establecer misiones de entrenamiento militar en otras repúblicas americanas; b) Proveer entrenamiento en los Estados Unidos para personal militar americano; c) Participar en la elaboración conjunta de planes para la defensa hemisférica; d) Proveer equipamiento militar a otras repúblicas americanas (USDS, FR, 1950, Vol I,,629).

A partir de esta declaración de Truman, se llevaron a cabo conversaciones entre miembros de las fuerzas armadas de Estados Unidos y de América Latina para evaluar la fuerza militar real en la región. En mayo de 1946 se estableció cuál sería el equipo necesario para mejorar la situación militar de América Latina. Desde ese momento, Estados Unidos reforzó su posición como proveedor militar de las naciones al sur del río Bravo, particularmente en materia de entrenamiento (USDS, FR, 1950, Vol I, 630). En otro mensaje de Truman al Congreso (ya finalizando su presidencia), el mandatario aclaraba que estos lineamientos tenían por objetivo mantener "la paz y la seguridad" continentales, y que Estados Unidos debía evitar impulsar el establecimiento de 
bases militares que excedieran los requisitos de seguridad: "este gobierno no participará de una distribución irrestricta e indiscriminada de armamentos que puedan contribuir a una carrera armamentista inútil y pesada" (Boletín Departamento de Estado, 1952: 403). Sin embargo, no se concretó una ley específica al respecto, y la asistencia militar para América Latina se canalizó a través de un programa intermedio mediante el cual se ofrecían a la venta cantidades limitadas de equipo excedente a países de América Latina en el marco de la Ley de propiedad excedente; este programa intermedio caducó en 1948 (USDS, FR, 1950, Vol I, 628)

Con base en estos antecedentes (respondiendo a los intereses internos y a la política de "contención" de la expansión soviética), en enero de 1949 el presidente Truman solicitó al Congreso apoyo para implementar acuerdos regionales de defensa, con el fin de aumentar la asistencia militar (USDS, FR, 1950, Vol I, 601). Un año después (enero 1950), el Departamento de Estado envió a las embajadas de las repúblicas americanas un informe explicando la aplicabilidad de la Ley de Asistencia para la Defensa Mutua, sancionada en octubre de 1949.

\subsection{INJERENCIA EN ASUNTOS INTERNOS: ESTANDARIZACIÓN MILITAR Y EL NEGOCIO DE LAS ARMAS}

A principios de la década de 1950 entró en vigencia la Ley de Asistencia para la Defensa Mutua, pensada para vender a otras repúblicas americanas equipos compatibles con sus condiciones económicas y con las necesidades de la "defensa hemisférica". Autorizó la transferencia de equipos por medio de ventas a países que hubieran ratificado el TIAR, pero "sólo sobre la base de pago efectivo reembolsable del costo original, incluyendo refacciones y cargos por servicios" [volveremos a este punto más adelante] (USDS, FR, 1950, Vol I,, 628).

En el marco de las discusiones sobre el tipo y la cantidad de asistencia militar que debía brindarse a América Latina, una de las propuestas desde el Departamento de Defensa y los Jefes del Estado Mayor Conjunto (Joint Chief of Staff, JCS), fue la de "estandarizar" las fuerzas armadas a nivel continental, como parte de las obligaciones contraídas en los acuerdos de seguridad colectiva como el TIAR. Esta estandarización pretendía lograr una cierta "homogeneidad" en cuanto a entrenamiento, cantidad, tipo de armas y rol de las fuerzas armadas a nivel continental. Conocer un poco más sobre este punto es fundamental, en tanto es un claro antecedente de la "estandarización masiva" que se dio entre este período (principio de los 50 y finales de la década de 1970), sentando las bases de la Doctrina de Seguridad Nacional implementada en varios países de América Latina.

Es importante mencionar que la estandarización militar implica la injerencia en asuntos de las fuerzas armadas de otros países, ya que define la cantidad y el tipo de armas y entrenamiento que deben recibir los militares. De hecho, esto era asumido por el mismo Departamento de Estado, que advertía que una de las consecuencias de este plan era que Estados Unidos corría el riesgo de ser acusado por "intervenir en asuntos internos de otros países. Estados Unidos no 
puede dictar a los países Latinoamericanos en asuntos tan cercanos a la independencia soberana como es la defensa nacional" (USDS, FR, 1950, Vol I,: 618, subrayado propio). Asimismo, el representante de Estados Unidos frente a la OEA, John Dreier, sostenía que la propuesta de un plan de seguridad hemisférico tal como se solicitaba a la Junta Interamericana de Defensa (Inter American Defense Board, IADB) sería perjudicial para las políticas económicas en el área y para las relaciones con los países de América Latina en general (USDS, FR, 1950, Vol I, 623)

En el marco de la asistencia militar, se inclúa el entrenamiento de tropas de América Latina, que fue lo que se implementó de modo sostenido desde fines de la Segunda Guerra Mundial. Es fundamental destacar que este entrenamiento era financiado por los gobiernos de América Latina (Boletin Departamento de Estado, 1953, 464). Esta situación invita a reflexionar sobre el concepto de "asistencia", ya que Estados Unidos no estaba "asistiendo" (según la acepción altruista y desinteresada del término), sino que brindaba un "servicio" que entonces había que pagar.

Con la "asistencia" en armas sucedía algo similar, si consideramos los requisitos que debían cumplir los países de la región para contar con la venta/préstamo de armas estadounidenses. En este sentido, había tres aspectos clave: las formas de pago, la venta de armamento obsoleto y la conveniencia o no de aumentar el presupuesto para asistir militarmente a América Latina teniendo en cuenta las condiciones económicas y políticas de los países de la región.

La venta de armas a los Estados latinoamericanos estaba regulada por la sección 408 (e) de la Ley de Asistencia para la Defensa Mutua, donde se especificaba la ayuda reembolsable para las naciones que tuvieran acuerdos regionales y colectivos con Estados Unidos (USDS FR, 1950, Vol I, 620-621).

En un informe del Consejo de Seguridad Nacional (National Security Council, NSC), se planteaba lo siguiente con respecto a las precauciones que había que tener en la asistencia para América Latina:

"Considerando la experiencia de colaboración militar a países de América Latina desde la guerra, se demostró que muchos países deseaban equipos por montos que excedían sus capacidades económicas. Algunos países latinoamericanos están sobrepasados por obligaciones financieras que no pueden enfrentar, muchos tienen escasez de dólares, tiene una posición precaria en el mercado internacional; buscan la asistencia de Estados Unidos para resolver estos problemas y la están recibiendo por medio de préstamos y proyectos económicos constructivos pero caros (...) [Por otra parte] cuando los países de América Latina son incapaces de expandir su presupuesto para obtener equipo militar de Estados Unidos, se vuelcan a cualquier mercado disponible (incluyendo las naciones satélite de la URSS)" (USDS, FR, 1950, Vol I, 629-630). 
De este párrafo se desprenden varias cuestiones: 1) que había una conciencia clara con respecto a la frágil situación económica de América Latina; 2) que los programas de asistencia económica eran caros; 3) que América Latina compraría las armas a otros países, incluido los del bloque soviético, si Estados Unidos no se las vendía en mejores condiciones, en detrimento del pretendido programa de estandarización. Así las cosas, si bien la situación económica y política de América Latina podía ser "muy preocupante" (por ejemplo para la visión de algunos funcionarios del Departamento de Estado), no había discusión con respecto a que Estados Unidos debía impulsar mejores condiciones de pago y aprovisionamiento de armas para América Latina.

En su primer informe sobre Programa de Seguridad Mutua (en el cual se enmarcaba la Ley de Seguridad Mutua), Truman destacaba la importancia de los aliados en la lucha contra el comunismo: "Sin sus fuerzas armadas, las bases en sus tierras, y las materias primas de sus minas y selvas, nuestro poder militar estaría gravemente obstaculizado para defender a Estados Unidos y toda nuestra economía sería gravemente debilitada (...) por eso nuestra asistencia a otras naciones no proviene de la caridad" (Boletín del Departamento de Estado, 1952, 403, subrayado propio). Es importante notar que se hace referencia nuevamente a la relación entre seguridad y recursos, y el rol de América Latina en este esquema.

En el marco de este programa, se generó, efectivamente, un despegue de la ayuda militar legalizado también por el NSC 68, que llamaba a ampliar los programas de defensa y asistencia militar $^{8}$. De este modo, mientras la asistencia militar para Europa había consistido en un tercio de los 28 mil millones de dólares asignados en el contexto del Plan Marshall (1949-1952), durante los ocho años siguientes, consistió en más del 50 por ciento de un total de 43 mil millones de dólares (Encyclopedia of American Foreign Relations, 2011).

En lo relativo a América Latina, este programa definía "tres tipos" de ayuda militar (una reclasificación de lo que ya se venía organizando y aplicando al menos desde fines de la Segunda Guerra Mundial): 1) subsidios directos en equipos y otra asistencia a determinados países para prepararse para misiones especiales de defensa Hemisférica; 2) oportunidades para com-

8. Con el NSC 68 se pasó de la "contención selectiva" (que predominó entre 1946 y 1949) a la "contención global" a inicios de los '50 (Insulza, 1982). El documento planteaba lo siguiente: "Nuestra política general, en este momento, debe ser descrita como diseñada para impulsar un ambiente mundial en el cual el sistema americano pueda sobrevivir y florecer. Por ello rechaza el concepto de aislamiento y afirma la necesidad de nuestra participación en la comunidad mundial (...) En lo que respecta a la política de contención, se trata de una política que busca por todos los medios, excepto la guerra: 1) bloquear el aumento de la expansión del poder soviético; 2) exponer las falsedades de las pretensiones soviéticas; 3) inducir a una retracción del control y la influencia del Kremlin; 4) en general, impulsar las semillas de destrucción del sistema soviético al punto de lograr modificar su comportamiento para que se adecue a los estándares generalmente aceptados a nivel internacional..." (The National Security Council Paper № 68, NSC-68 en Griffinth y Backer, 2001: 305-307). 
prar armas a Estados Unidos y equipo que requería América Latina para la defensa hemisférica; 3) el establecimiento de la marina, la fuerza aérea y el ejército estadounidense para entrenar a las fuerzas armadas latinoamericanas (Boletín del Departamento de Estado, 1953: 464). En el marco del inciso dos, se permitían compras a Estados Unidos en efectivo cuando fueran aprobadas por los funcionarios estadounidenses, según lo establecido en la Ley de asistencia para la seguridad mutua, sin ser modificado lo relativo al "modo de pago", que siguió siendo sobre bases "reembolsables contra entrega".

En los documentos que exponen los principales objetivos de la asistencia militar para América Latina, se dejaba en claro que "la provisión de armamentos a gobiernos de América Latina debe incluir la autorización para la provisión, sobre bases reembolsables, de armamentos, refacciones y municiones necesarias para evitar el deterioro de las fuerzas armadas y para proveer un modesto aumento de armamentos justificado por el mantenimiento de la seguridad interna" (USDS, FR, 1950, Vol I, 605 subrayado propio).

Es fundamental destacar el modo en que aparece la seguridad interna atada a la suerte de la seguridad hemisférica, pues la inestabilidad política y económica interna, podía poner en peligro la seguridad continental, y obstaculizar el flujo de materias primas hacia Estados Unidos:

"Con respecto al rol de la defensa hemisférica, se espera que las fuerzas armadas de América Latina sean capaces de mantener la seguridad al interior de sus propios territorios, incluyendo la prevención de disturbios revolucionarios, operaciones clandestinas enemigas, defensa contra ataques y sublevaciones, protección de las fuentes de materiales estratégicos, protección de las vías de comunicación, seguridad local de las bases militares y suplementos militares (USDS, FR, 1950, Vol I, 637638, subrayado propio).

Vale recordar que este refuerzo hacia la asistencia militar y el consiguiente rol primordial asignado a las fuerzas armadas, se daba en el marco de la expansión del sistema capitalista de posguerra respaldado en la expansión de le economía de guerra al interior de Estados Unidos y por medio de esta asistencia al exterior, que

“...desde 1945 ha ascendido en promedio a más de 2 mil millones por año. Llegó a los 5 mil millones en el año 1952 y cayo al nivel más bajo de 831 millones de dólares en el año 1956. El número de países receptores se elevó de 14 en el año 1950 a un pico de 69 en el año 1963. En total, unos 80 países han recibido una suma de 50 mil millones de dólares en ayuda militar desde la segunda guerra mundial hasta hoy [1969]" (Magdoff, 1975: 79-80). 


\section{ASISTENCIA PARA EL “DESARROLLO" Y ASISTENCIA MILITAR}

En marzo de 1942 se creó el Instituto de Asuntos Interamericanos, primera entidad de asistencia técnica de Estados Unidos para otros países y regiones, anterior al Plan Marshall. Debemos recordar que también el TIAR, tratado de seguridad mutua fue firmado antes que la OTAN (abril, 1949). En este sentido, América Latina se presentó como "laboratorio" tanto en el campo de la asistencia "técnica para el desarrollo" como en el plano de la "seguridad colectiva".

El tipo de relación económico-política entre América Latina y Estados Unidos en los primeros años de la guerra fría, continuaba la dinámica centro periferia establecida en las relaciones interamericanas desde fines de siglo $\mathrm{XIX}^{9}$, sólo que en una coyuntura de aumento de precios de algunas materias primas ${ }^{10}$. Según el reporte de la Oficina de Asuntos Interamericanos, en 1950 América Latina había exportado a Estados Unidos 2.8 mil millones de dólares en bienes, el 35\% de las importaciones totales de Estados Unidos, incluyendo alimentos básicos como café y azúcar. América Latina proveía el $25 \%$ del total de las importaciones de Estados Unidos de metal y manufacturas; el $46 \%$ de la importación de lana; el $61 \%$ del petróleo y más del $50 \%$ de las importaciones de cobre, plomo, nitrato y fibra de henequén (USDS, FR, 1951, Vol. II, 952). Estos datos muestran con bastante claridad la importancia de las materias primas latinoamericanas para la economía estadounidense, y con ello, la vitalidad de garantizar el flujo de las mismas.

A cambio, las exportaciones de Estados Unidos a América Latina en 1950 totalizaron los 2.5 millones de dólares, el 30\% de las exportaciones totales de Estados Unidos en maquinaria; el $30 \%$ en hierro y acero; $38 \%$ en químicos, $40 \%$ manufacturas textiles; $44 \%$ en automóviles y $44 \%$ en manufacturas de hierro y acero (USDS, FR, 1951, Vol. II, 952). Estos datos también permiten corroborar el rol primario-exportador de América Latina, e importador de manufactura, situación que estaba experimentando algunas modificaciones, especialmente a partir de los procesos de Industria Sustitutiva de Importaciones (ISI) y de mecanismos para fortalecer los

9. Ver: Martí, 1973; Perkins, 1964; Romano, 2008.

10. El estatus de "primario-exportadora" obedece a la dinámica de "acumulación originaria" implicada en la expansión del comercio y el "descubrimiento" y colonización de nuevos espacios por parte de los europeos. Retomando a Bagú, Gunder Frank sostiene que "La revolución comercial, que se inicia en el siglo XV, al multiplicar el capital mercantil y estimular su vocación internacionalista, vinculó la suerte de un país con la de otro, intensificando su interdependencia económica (...) Si alguna característica bien definida e incuestionable podemos encontrar en la economía colonial es la de la producción para el mercado. Desde los primeros tiempos del régimen hasta sus últimos días, ella condiciona toda la actividad productiva [e implica] subordinación al mercado extranjero [que] ha sido y sigue siendo el principal factor de deformación y aletargamiento" (Bagú en Gunder Frank, 1965). Sunkel y Paz agregan que este impulso hacia la exportación de materias primas y la importación de manufacturas se sustentó en las premisas del librecambismo, debilitando en buena medida a las industrias locales nacientes. Estas condiciones dieron lugar a lo que se denominó economías "monoexportadoras", muy vulnerables ante las fluctuaciones de precios del mercado internacional (Sunkel y Paz, 1980: 43-78). 
mercados internos (incluida la nacionalización de recursos y empresas) (Ver: Prebisch, 1949; Cepal, 1959; Cardoso y Faletto, 1973) ${ }^{11}$.

Queda clara la diferencia en la composición de las exportaciones y exportaciones de Estados Unidos y América Latina. En efecto, en el mismo informe se afirma: "Las importaciones provenientes de Estados Unidos representaron el 50\% del total de las importaciones de todos los tipos, dando a conocer el alto porcentaje de dependencia por parte de América Latina de los suministros de Estados Unidos" (USDS, FR, 1951, Vol. II, 952).

Es importante señalar que durante la primera mitad de 1953 se debatieron varios proyectos de ley para asegurar el aumento en la protección de productos estadounidenses como petróleo, pescado, zinc, plomo y otros que América Latina exportaba a esta nación (Boletín Departamento de Estado,1953: 780) ${ }^{12}$. Como se planteaba en otro informe de la Oficina de Asuntos Regionales Interamericano: "Los Estados Unidos no se oponen a la necesaria justicia en los precios, pero sostiene que en los últimos años, se han favorecido los precios de las materias primas y no los de las manufacturas" (Boletín Departamento de Estado, 1953: 718). Esto parece atinado desde una visión coyuntural en un período de aumento de los precios de las materias primas; sin embargo, en un análisis estructural y de largo plazo, existe una enorme diferencia entre las economías exportadoras de manufacturas y bienes de capital, y economías exportadoras de materias primas, diferencia a favor de las primeras ${ }^{13}$.

11. Según el análisis de Prebisch, las ventajas comparativas y el libre comercio, no llevarían por sí solos al "despegue" (la industrialización) de las economías latinoamericanas. Era indispensable la participación (intervención) del Estado como planificador de la economía, considerando que: relaciones centro-periferia se planteaban como inherentemente asimétricas; el desarrollo capitalista en la periferia era diferente al de los centros; se necesitaba un cambio en la estructura social de América Latina destinado a paliar la acumulación de la riqueza (que no implicaba acumulación de capital, sino exagerado consumo de los estratos superiores); redistribución del ingreso a nivel social y geográfico; aceleración del ritmo de desarrollo económico y redistribución del ingreso a favor de las masas, teniendo en cuenta que el desarrollo económico debía ir en conjunto con el desarrollo social (Prebisch, 1949).

12. La tendencia al proteccionismo en los países centrales fue cada vez más marcada: en Europa, la importación de productos primarios (hacia 1960) decayó al 57 por ciento del total de las importaciones, mientras que en 1970 disminuyó al 35 por ciento de dicho total. En Estados Unidos se siguió esta misma tendencia, ya que entre 1870 y 1913 este país dedicaba el 65 por ciento de sus importaciones a los productos primarios, disminuyendo a los porcentajes apuntados para Europa entre 1960 y 1970 (Ferrer, 1976: 29, 33-34)

13. Tales tendencias proteccionistas hacia el interior de los Estados centrales, se implementaron de manera simultánea a la instauración del orden económico internacional de posguerra acordado en Bretton Woods, orientado a la liberalización de los mercados. De este modo, convivieron por un lado, las políticas económicas internas de los países desarrollados, orientadas al pleno empleo para evitar otra crisis como la del '30, con la doctrina de liberalización a nivel de relaciones económicas con los demás Estados centrales (Dell, 1984: 7). Esta dinámica profundizó las asimetrías en el comercio internacional, aspecto que fue puesto de manifiesto en la Asamblea General de las Naciones Unidas (a fines de 1952), en la cual se aprobó una resolución que trataba acerca del financiamiento del desarrollo económico mediante el establecimiento de precios internacionales "justos y equitativos" para los artículos de primera necesidad. Las dos terceras partes de la Asamblea (mayoría necesaria para aprobar la resolución) se formó con los países subdesarrollados, los países industrialmente avanzados (mucho menos numerosos) votaron en contra de dicha resolución. Esto llevó a Myrdal (1964: 315) a afirmar que: "En el terreno internacional no hay nada 
Este evidente "desequilibrio" sería balanceado por medio de la "asistencia para el desarrollo"; así lo manifestaba el presidente Eisenhower: "Nuestra política comercial es sólo una parte fundamental de un problema más amplio. Este problema implica la necesidad de desarrollo por medio de la cooperación entre las naciones libres, un sistema económico autosuficiente, capaz tanto de promover la fuerza militar para contener la agresión, como de aumentar la productividad de modo que se mejoren los estándares de vida" (Boletín Departamento de Estado,1953.719).

Esto ya había sido "notado" por Truman, quien lanzó un plan de asistencia para los países subdesarrollados, muy diferente al Plan Marshall, el Punto IV. Este plan se llamó así porque era el cuarto de una serie de nuevas proposiciones para alcanzar la "paz y la libertad" en el discurso inaugural del presidente Truman, el 21 de enero de 1949. Surgió para responder a los siguientes objetivos: proporcionar a los "países menos desarrollados" tecnología y administración, detener el comunismo en el tercer mundo, salvaguardar las inversiones extranjeras de Estados Unidos y aumentar la producción de materiales estratégicos (Pollard, 1990: 198).

Uno de los objetivos de la asistencia oficial estadounidense era promover las condiciones para que "fluyera" el capital privado (esto indica la confluencia de los intereses del sector público y privado en pos de la expansión de la economía estadounidense): "La Ley para el Desarrollo Internacional [en la cual se enmarcaba el Punto IV] plantea que el gobierno de Estados Unidos debe impulsar y expandir la inversión privada (...) algo puede hacerse en términos de garantías, impuestos y tratados con diferentes países para dar mayor garantía a este capital" (Boletín Departamento de Estado, 1953:310). La cooperación era considerada como una "calle de dos vías", en tanto requería del "esfuerzo" del pueblo norteamericano por invertir en las repúblicas hermanas, a la vez que implicaba buenas condiciones de inversión en los países receptores (Boletín Departamento de Estado, 1953:,461).

La asistencia para el desarrollo no estaría orientada a una "rápida industrialización en América Latina", sino que mas bien debía dirigirse a incrementar la producción agrícola (Rabe, 1988:19) y a generar las condiciones para el flujo de recursos energéticos y minerales, planteo coherente con el rol geopolítico y geoeconómico que Estados Unidos había asignado a América Latina en la guerra fría: proveedora de materias primas y recursos estratégicos, y no como espacio productor de manufacturas competitivas. Se mencionó más arriba que la asistencia era uno de los caminos para crear las condiciones propicias para el flujo de capital privado; así, la inversión estadounidense en América Latina a principios de 1950 alcanzaba los 6 mil millones de dólares (el $40 \%$ del total de la inversión extranjera directa de Estados Unidos), presupuesto que en su

parecido a la solidaridad en la actitud de los países prósperos hacia los pueblos y las industrias de los países subdesarrollados". Por otra parte, esto también había cobrado importancia en ocasión de la asamblea de Bretton Woods, cuando Lord Keynes, además de proponer la constitución de un fondo financiero internacional, planteó la necesidad de establecer una "Agencia Internacional para el Control de Commodities", a fin de organizar los stocks de materias primas a nivel internacional (Singer, 1984: 15) 
mayor parte se derivó hacia la economía extractiva, como el cobre de Chile y el petróleo de Venezuela (Rabe, 1988:76).

Un funcionario estadounidense remarcaba que si bien había países que se quejaban con respecto al capital extranjero, "hay otras repúblicas dispuestas a cooperar (...) muchos países se mostraron preocupados por el creciente ataque al capital extranjero en algunos Estados" (Boletín del Departamento de Estado, 1953: 461). No debe olvidarse las medidas de nacionalización, protección de los mercados internos y aliento a la producción local, en sus muy diversos matices, implementadas por Vargas en Brasil, Perón en Argentina, la experiencia vivida en el México de Cárdenas, la "revolución boliviana" y las propuestas del gobierno de Arbenz en Guatemala, por mencionar algunos casos (González Casanova, 1979; Di Tella, 1993).

Minimizando la discusión al respecto, los funcionarios estadounidenses afirmaban que prácticamente todos los países del continente acordaban en la importancia del capital para los países subdesarrollados. El problema residía en que

"Las gentes al sur de Estados Unidos buscan con determinación mejorar sus condiciones materiales (...) se dan cuenta de la necesidad de llevar a cabo reformas sociales para corregir abusos históricos y no es sorprendente que las compañías extranjeras sean unas de las víctimas de estas reformas (...) Pero es nuestro deber demostrar que las inversiones estadounidenses son beneficiosas para los pueblos que las reciben (...) Ya que los problemas de América Latina son económicos, sabemos que se pueden resolver con la inversión, lo ideal sería "el flujo de capital privado en una atmósfera de confianza mutua" (Boletín del Departamento de Estado, 1953: 462).

En síntesis: lo que debían garantizar los países receptores de capital, era la presencia de condiciones suficientes para salvaguardar las inversiones estadounidenses.

¿Cómo se relacionaba este escenario con los planes de seguridad para la región? Es importante señalar la vinculación que se dio entre la asistencia militar y la expansión del capital estadounidense, por medio de la Ley para la Seguridad Mutua y los posteriores acuerdos que el gobierno estadounidense firmó en el marco de esta ley con aquellos países que recibieron inversiones de empresas norteamericanas. De este modo, era el Estado quien se exponía como garante del cumplimiento de las condiciones necesarias para asegurar la inversión en el extranjero (Morray, 1970). Esta dinámica pone de relieve la articulación entre intereses públicos y privados en la política externa de Estados Unidos hacia la región (que era un fiel reflejo de la consolidación de la elite del poder a nivel interno liderada por la cúpula de las fuerzas armadas, del empresariado y de la política). En casos como el de Guatemala (1951-1954), las medidas tomadas por el gobierno estadounidense para salvaguardar los intereses privados de 
la United Fruit Company, incluyeron estrategias de desestabilización, golpe de Estado y complicidad con el gobierno militar de Castillo Armas (Gleijeses, 1991; Schlesinger y Kinzer, 1984; Jonás, 1979).

La asistencia "oficial" era una forma de impulsar la inversión en el extranjero (promover la política de "puertas abiertas") ${ }^{14}$ pero para ello eran necesarias ciertas condiciones locales, siendo la "estabilidad" uno de los requisitos más importantes. Y esto se complementaba con los objetivos clave de la asistencia militar orientados a garantizar la producción, obtención y flujo de materias primas. Por ejemplo, para ello había que lograr la "expansión y desarrollo de materiales críticos y las instalaciones asociadas a energía y transporte", lo cual requería de una inversión de 350 millones de dólares por año. De este total, se pensaba desde el gobierno que 125 millones podrían ser aportados por el BIRF, mientras que los 225 millones restantes serían proveídos por el gobierno estadounidense por medio de préstamos. Asimismo, se esperaba asistir para el aumento de la producción de alimentos (para lo cual ya habían sido destinados 20 millones en 1952 y serían asignados 30 millones en 1953), para el incremento de las actividades del Punto IV en otros rubros (para lo cual debería destinarse 20 millones por año) y destinar 20 millones para un fondo en caso de eventos impredecibles como "terremotos, inundaciones y disturbios" (USDS FR, 1950, Vol I, 650).

Después de esta descripción se solicita una ayuda adicional de 164 millones (para el período 1951-1955). De esta suma, 64 millones serían utilizados para completar el tramo superior de la autopista Panamericana y el resto (100 millones) serían destinados a cubrir las necesidades de transporte que surgirían debido al esfuerzo en un aumento de la producción a lo largo de América Latina (USDS FR, 1950, Vol I, 660). Una síntesis de esto se aprecia en uno de los discursos de Truman sobre los objetivos del Programa de Seguridad Mutua: "garantías para la inversión estadounidense en el extranjero, excedentes agrícolas, cumplimento del 50-50 para la bandera estadounidense en lo relativo a transportes, ayuda a las pequeñas empresas; adquisición de material estratégico" (Boletín del Departamento de Estado, 1952: 473)

Con respecto a las agencias internacionales vinculadas a la asistencia, además del caso del BIRF mencionado más arriba, en un informe sobre las actividades del ExIm Bank realizadas a lo largo de 1952, se explicaba que más de la mitad del crédito de este banco se había destinado a préstamos para el desarrollo de fuentes de "materiales estratégicos" en el exterior, monto que alcanzó los 314.2 millones de dólares de un total de 596 millones de dólares prestados por este banco. Las ganancias netas fueron de 26 millones para los últimos 6 meses de 1952, siendo las ganancias totales para el año 1952 de 50.7 millones de dólares (Boletín Departamento de Estado, 1953:222).

14. Ver: Appleman Williams, 2007 


\section{SEGURIDAD Y “DESARROLLO": EL CAMINO A LA DEMOCRACIA (DE MERCADO)}

A partir de lo expuesto puede percibirse la vinculación de los programas de asistencia y la concepción de seguridad nacional de Estados Unidos, que, a su vez, definía los objetivos, alcances y limitaciones de la seguridad hemisférica. La legitimidad de esta articulación descansaba en buena medida en los "valores occidentales" que había que defender, preservar y expandir en el marco del conflicto bipolar, algo así como la dimensión "ideológica" de la expansión del capitalismo monopólico hacia la periferia. La importancia de articular la democracia con los valores liberales para justificar ciertas medidas de seguridad en el orden bipolar, había sido mencionada por Truman en diversas oportunidades (Boletín Departamento de Estado, 1952: 404).

El Departamento de Estado asumía que estos valores debían complementarse con lineamientos para el desarrollo como herramienta contra la infiltración comunista: "Lo que se necesita son gobiernos representativos que lideren el apoyo a sus pueblos, fuerzas policiales eficientes inmunes a la infiltración comunista; mejoras económicas y sociales y el aumento de calidad de vida que proveerá un mayor apoyo a gobiernos estables y la consiguiente mantención del orden..." (Boletín Departamento de Estado,1952: 619, subrayado propio).

En un informe de la Administración para la Cooperación Técnica, se planteaba i"Cuáles son las normas y varas de medida que debemos utilizar para medir los grados de desarrollo? (...) Todos nosotros necesitamos implementar una mirada mas profunda del problema, no solo desde el punto de vista del 'interés privado y la ganancia', que es importante, sino que nuestro interés nacional y los estándares de vida dependen de estas. No podemos vender algo a una persona que no tiene nada" (Boletín del Departamento de Estado, 1953: 307). O sea: lo importante era garantizar un mercado de consumo, promover el aumento de consumidores. Más adelante, se amplia esta idea: "Hay una sola forma de elevar los estándares de vida generales de cualquier área y esto es por medio de un aumento en el uso de bienes y servicios -en otras palabras, aumentar la producción de alimentos, fibras para ropas, materiales para construcción y otros productos que el país pueda intercambiar con otros países- a los fines de que todos puedan tener más" (Boletín del Departamento de Estado, 1953: 308). Aquí también queda claro que el esfuerzo tiene que hacerse en la producción primaria y el comercio, llegando a la conclusión de que esa dinámica, por sí misma, llevaría a que "todos" pudieran "tener más.

En un documento de la Oficina de Asuntos Interamericanos, previos a la Cuarta Reunión de Ministros (marzo-abril 1951), se advertía que "los reclamos de las repúblicas americanas vendrán por el lado de lo económico", se aclara que los programas de cooperación técnica deben servir para "ayudar a los países latinoamericanos a que se ayuden a sí mismos" a superar la pobreza, la ignorancia y las enfermedades. La cooperación técnica buscaría ayudar a la planificación, al aumento de la productividad laboral, para la creación de riqueza con el objetivo de mejorar el bienestar económico y social (USDS FR, 1951 Vol II, 954). 
Así, desde la visión de los funcionarios estadounidenses, el desarrollo consistía en la incorporación de consumidores al mercado, a la vez que implicaba la posibilidad de optimizar la inserción de América Latina en el mercado internacional como productor-exportador de materias primas. Pero además, teniendo en cuenta lo expuesto hasta aquí sobre el rol geoestratégico de América Latina, desarrollo significaba "desarrollo para la producción y distribución de materiales de defensa, de modo constructivo" (USDS FR, 1951 Vol II, 954-955). Porque el "mundo libre" tenía que apoyar el "rearme" impulsado por Estados Unidos para "contener" a la Unión Soviética y mantener el complejo industrial-militar como base de la expansión del capitalismo monopólico (Baran y Sweezy, 1974; Magdoff, 1975; Miliband, 1970).

Desde esta postura, también se definía aquello que "no era" desarrollo, según los intereses estadounidenses. Para el caso de América Latina, el nacionalismo y algunos "reformismos" eran lo contrario a desarrollo. John M. Cabot era enfático al respecto: "No necesito decirles que el nacionalismo ha herido más que ayudado a América Latina, no produjo los beneficios nacionales ni para los trabajadores ni para las economías nacionales en su conjunto, que sí fueron producidos por las compañías privadas" (Boletín del Departamento de Estado, 1953: 462).

Deben recordarse aquí las enormes consecuencias que tuvieron tales medidas, pues desde el golpe de Estado a Arbenz (1954) hasta el golpe militar en Chile (1973), uno de los factores clave en los procesos de desestabilización de tales gobiernos, fueron los lineamientos para la nacionalización de recursos naturales y empresas.

En este esquema, el gobierno estadounidense planteó una relación causa-consecuencia entre subdesarrollo e (in)seguridad. En las metas del Punto IV esto se expone de la siguiente manera: "El presidente Roosevelt decía que la 'pobreza en cualquier lado constituye un peligro para la prosperidad en todos lados (...) y se puede agregar que el miedo a la agresión en cualquier lado constituye un peligro para la paz en todos lados" (Boletín del Departamento de Estado, 1949, 243). Como lo expresaba Malembaum, jefe de Departamento de Inversión y Desarrollo Económico: "El hambre y la pobreza, la desesperación y falta de esperanza alimentan a los aliados de las fuerzas antidemocráticas" (Boletín Departamento de Estado, 1953: 371). De este modo, los programas de asistencia económica y técnica eran una de las alternativas para garantizar la "estabilización" de los países menos desarrollados (que podían amenazar la seguridad interna de Estados Unidos).

\subsection{LA DEMOCRACIA “POSIBLE" EN AMÉRICA LATINA Y EL MODELO ESTADOUNIDENSE}

Para comprender el alcance de la promoción de la democracia en América Latina durante los primeros años de la guerra fría, es importante considerar la relación de la democracia liberal procedimental estadounidense con el sistema capitalista desde sus orígenes, y -entonces- su tendencia elitista (Meiksins Wood, 2000: Zinn, 1999), que se exacerbó con el Macartismo y el Estado de Seguridad nacional legalizado y legitimado por la guerra fría (Wills, 2010). Esta de- 
mocracia limitada formó parte del "modo de hacer las cosas" del gobierno estadounidense según el cual la ley no era lo primordial, sino el poder. La Ley, según declaró el secretario de Estado Acheson, "no puede negociar con cuestiones de poder. La supervivencia de los Estados no es una cuestión de ley sino de poder" (Lafeber, 1989:443). Si el poder estaba por encima de la ley, pues se hacía compleja la instauración de una democracia que en la práctica implicara participación e igualdad.

Mientras tanto, en América Latina se experimentaba una breve "primavera democrática" en la que se reivindicaron derechos de participación política, pero también de inclusión económica de las mayorías (Joseph, 2004). No obstante, fueron dos años, como lo sostiene Gleijeses (1991: 99), “En 1945 y 1946 la administración Truman mostró antipatía frente a regímenes dictatoriales y se mostraba de acuerdo con la política de los regímenes democráticos en América Latina. Para 1948 esta postura cambió por un apoyo a las dictaduras como mejor defensa en contra del comunismo". Se llevó a cabo la intervención y la desestabilización en nombre de la democracia, contra aquellos gobiernos que no satisfacían las necesidades estadounidenses. Como lo sostiene Rabe (1988: 37), la administración Eisenhower no sólo trabajó con los denominados gobiernos dictatoriales, sino que los apoyó efusivamente.

Las implicancias de la intervención en nombre de la democracia a favor de los intereses estadounidenses coincidía con la doble moral avalada por la teoría realista ${ }^{15}$ : "en general, y en ocasiones apropiadas, hemos aconsejado en declaraciones públicas que la democracia debe ser alcanzada por medio de un proceso de crecimiento y desarrollo internos y que no puede ser impuesta desde afuera" (USDS FR, 1951, Vol II, 1423).

Se explicó más arriba la enorme importancia del acceso a determinadas materias primas y cómo esto generaba la necesidad de garantizar la seguridad interna. Esta necesidad podía ser atendida por regímenes democráticos que no cuestionaran las relaciones con Estados Unidos, o por gobiernos militares. Cuando un gobierno no respondía a los intereses estadounidenses, se alegaba que estaba "infiltrado por el comunismo" y que no era democrático (aunque hubiese sido elegido mediante el voto de la mayoría). Hay que recordar que a diferencia del "imperialismo" (como lo denomina González Casanova (1979) a la expansión del capitalismo estadounidense), el comunismo buscó la forma de asociarse a los movimientos nacionalistas a lo largo de la región, como estrategia para reforzar su debilidad como partido y así lograr presentarse a los comicios. El gobierno estadounidense sostenía que el problema era la "infiltración" del comunismo en otros partidos de izquierda y en sindicatos (sobre todo, aquellos que impulsaban ideales nacionalistas y antiimperialistas), constituyendo por lo tanto, una "amenaza interna" (y no necesariamente externa:

15. Ver nota al pie no 3

SEGURIDAD HEMISFÉRICA, ASISTENCIA Y DEMOCRACIA A INICIOS DE LA GUERRA FRÍA 
"Si bien el ejército soviético puede no ser una amenaza inmediata para este hemisferio, siempre debemos estar preparados para enfrentar un ataque aéreo o naval (...) Además, los agentes del comunismo, activos a lo largo de las Américas constituyen una amenaza interna (...) uno de sus principales targets son los programas de asistencia militar de Estados Unidos para América Latina. Incluso convencieron a algunos líderes de América Latina de que estos acuerdos violan los intereses para las repúblicas americanas. Nuestro mejor método para enfrentar esta propaganda a nivel de opinión y en los hechos es explicarles estos programas a los pueblos de América Latina y coordinarlos con asistencia técnica para el desarrollo económico" (Boletín del Departamento de Estado, 1953: 466).

En este sentido, se pone en evidencia la cuestión de la seguridad como seguridad interna, la importancia de la asistencia militar, y la necesidad de "coordinarlas" con asistencia para el desarrollo. Por eso una de las preocupaciones de los funcionarios estadounidenses durante los primeros años de la guerra fría era la "tendencia nacionalista" de algunos gobiernos de países menos desarrollados de Asia y América Latina, y las consecuencias que ello podría tener para la inversión privada de Estados Unidos en dichos espacios. Y, curiosamente, esta "tendencia nacionalista" estaba vinculada (desde el punto de vista de los funcionarios estadounidenses) a la "inestabilidad" y a gobiernos "no democráticos" (Boletín del Departamento de Estado, 1949: 374).

Ante lo expuesto hasta aquí, notamos que la democracia era válida (desde la visión del gobierno estadounidense) sólo si garantizaba estabilidad, es decir, si no cuestionaba el orden instituido favorable a los intereses estadounidenses. La estabilización fue, precisamente, el eje de la "Doctrina de Seguridad Nacional" implementada de modo sistemático a partir de la década de 1960 en varios países de América Latina. Este punto es clave, en tanto es a partir del gobierno de Eisenhower, especialmente a partir del derrocamiento de Arbenz en Guatemala (1954), que se dio un giro de la "guerra total" a la "guerra limitada", giro que se profundizó durante el gobierno de Kennedy (1961-1963) (Tapia Valdés, 1980).

La DSN no fue solo un plan de estabilización política mediante la represión y el terrorismo de Estado, sino que implicó también políticas de liberalización económica, asociadas a la idea de "desarrollo" promovida por el gobierno estadounidense: apertura de los mercados, flujo de capital, acceso a materias primas y mano de obra barata, garantía de expansión de las transnacionales (Furtado, 1971).

La ecuación democracia y desarrollo-seguridad, se dirimió a favor de esta última. Si consideramos los Programas de Estados Unidos en América Latina en Cooperación Técnica y Actividades Relacionadas para el período 1950-1960, el total asignado fue de aproximadamente 267.8 millones de dólares (Mecham, 1961:368). En cuanto a la Asistencia militar y ventas militares de Estados Unidos a países de América Latina, para el período de 1953 a 1965, estas alcanzaron un 
total aproximado de 1.164 millones de dólares (Veneroni, 1971: 186). Incluso si se toman como referencia solamente los Programas de Asistencia Militar para América Latina entre 1950 y 1963, la suma es de 374.7 millones de dólares (Veneroni, 1971:187).

Esto no hizo más que contribuir a consolidar el modelo primario-exportador y dependiente, tal como lo marcaron no sólo los economistas de la dependencia y marxistas latinoamericanos, sino la misma CEPAL, remarcando no sólo lo perjudicial del deterioro de los términos de intercambio para las materias primas, sino aclarando que con la "asistencia" no sería suficiente:

"En efecto, la ilusión que pudo haberse tenido en los diez años posteriores a la segunda guerra mundial de que esta economía estaba adquiriendo un gran impulso de crecimiento se ha desvanecido desgraciadamente por completo (...) América Latina, por grande que sea la ayuda exterior, por fuerte que sea el ritmo de sus exportaciones -y no podrá serlo en otro grado- no estará en condiciones de cumplir su designio de crecimiento, ni podrá recuperar la tasa de crecimiento que tuvo en los diez años posteriores a la guerra, si no hace un esfuerzo sostenido en el sentido de crear en su propio seno las industrias de bienes de capital que con tanto apremio necesita en estos momentos" (CEPAL, 1959: XI).

\section{CONCLUSIONES: LOS HILOS DE CONTINUIDAD}

El anticomunismo caló profundo en la sociedad estadounidense y ciertamente fue el motor ideológico para legalizar los enormes gastos del complejo industrial militar para la guerra fría. Pues eran las potencias occidentales las que encarnaban la "democracia" y las verdaderas posibilidades de "desarrollo", frente al modelo comunista. La lucha era para liberar a los pueblos oprimidos. Sin embargo, como se ha revisado en este escrito, "la infiltración comunista" no era un problema en sí mismo, sino que implicaba una amenaza porque podía afectar las estructuras económico-sociales. La inestabilidad y los procesos de nacionalización de recursos amenazaban el flujo de recursos de América Latina hacia Estados Unidos, indispensables para mantener el complejo industrial-militar, en tanto respaldo de la expansión del capitalismo monopólico. De este modo, los lineamientos de asistencia para la seguridad y asistencia "técnica para el desarrollo" se conjugaron para garantizar los intereses privados y públicos del gobierno estadounidense en la región. La democracia y el desarrollo, según eran promovidos desde el Norte, resultaron estar al servicio de ciertos intereses, y no a favor de las mayorías.

Se mencionó en la introducción que luego de la desarticulación de la Unión Soviética, el enemigo interno se "recicló" de diversas formas: inestabilidad, crimen organizado, terrorismo, narcoterrorismo, etc. llamando la atención que cada vez cobra mayor evidencia el rol de América Latina como espacio primario-exportador: "La estrategia de búsqueda de materias primas ha sido impulsada por los altos precios de diversos productos básicos y se han dado importantes 
inversiones en toda la región, especialmente en América del Sur (...)En comparación con el período 2005-2009, en 2010 hay un mayor peso de los recursos naturales, lo que muestra una tendencia a la primarización de la IED" (CEPAL, 2011: 58).

Al mismo tiempo, los países centrales requieren cada vez más de recursos escasos para mantener sus niveles de consumo, la mayoría de ellos provenientes de la periferia, lo cual es claro especialmente para el caso de Estados Unidos. Según datos de Delgado Ramos (2010, 2010a), la importación de petróleo por parte de ese país del 28\% en 1973, a cerca del 55\% en 2003 y se calcula que para el 2025 será de un 70\%. Los principales países exportadores de crudo y sus derivados hacia Estados Unidos (según datos de 2007) son Canadá (con 19\%), México (15\%), Arabia Saudita (14\%), y Venezuela (13\%). Esto implica que en total, Canadá y AL suman el $50 \%$ de los cerca de 10 millones de barriles diarios que importa. Para dar una idea del ritmo de transferencia de crudo, el caso de México es más que manifiesto pues ha transferido más del $80 \%$ del crudo que exporta a EUA. Algo similar sucede con los minerales: en 1980 Estados Unidos dependía al 100\% de cuatro minerales y de 16 más en el orden de un $30 \%$ - 99\%. En 1992 tal dependencia era de 8 y 22 minerales respectivamente y, para 2009, de 19 y 26.

Ante este panorama, la militarización es una vez más la alternativa para garantizar el flujo de recursos, sólo que ya no se implementa en el marco de "guerra fría", sino en un esquema mucho más complejo en el que los Estados centrales, y especialmente Estados Unidos para el caso de América Latina, operan cada vez más por medio de sus multinacionales para garantizar el flujo de recursos, en complemento de la asistencia para el desarrollo y de la asistencia militar. Por otra parte, también existen hoy gobiernos en América Latina que plantean lineamientos orientados a la nacionalización de recursos y empresas bajo medidas de redistribución planteadas desde el Estado para beneficiar a las mayorías. Es sabido que estos gobiernos, como el de Chávez en Venezuela o el de Morales en Bolivia, han tenido que enfrentarse el establishment estadounidense en diversas oportunidades y han denunciado la intervención directa o indirecta de dicho país.

De este modo, vuelve a adquirir importancia el modo en que Estados Unidos define la seguridad, el desarrollo y la democracia (siempre subsumidos a la primera) y las diversas alternativas que se están implementando y proyectando desde algunos gobiernos latinoamericanos, que orientan sus políticas a la integración política, económica, étnica y cultural de mayorías históricamente excluida.

Por último, para repensar este presente es fundamental volver a ciertas preguntas, como cuándo empezó la guerra fría, si es que concluyó con la desarticulación de la Unión Soviética, si los lineamientos y prácticas implementados en dicho período se siguen aplicando en determinadas circunstancias, si los intereses subyacentes a las relaciones de Estados Unidos con América Latina se han modificado sustancialmente. 


\section{BIBLIOGRAFÍA}

- $\quad$ Adams, W. (1976). Los Estados Unidos de América México: Siglo XXI

- $\quad$ Appleman Williams, W. (2007). Empire as a way of life. New York: IG.

- $\quad$ Barbé, E. (1995) Relaciones Internacionales Madrid: Tecnos.

- $\quad$ Barnet, R. (1974). Guerra perpetua: Los hombres y las instituciones responsables de la política exterior de Estados Unidos. México: FCE.

- Busso, A. (2008). "Identidad y fuerzas profundas en Estados Unidos. Excepcionalismo, tradición liberal-tradición conservadora, aislacionismo-internacionalismo, política y religión: su impacto en la política exterior" en Busso A. (comp.) Fuerzas profundas e identidad. Reflexiones en torno a su impacto en la política exterior. Rosario: Universidad Nacional de Rosario.

- Carr, E. (1961). ¿Qué es la historia? Buenos Aires: Planeta-Agostini

- Cardoso F. H. y Faletto, E. (1973). Dependencia y desarrollo en América Latina. México: FCE.

- $\quad$ CEPAL (1959). El Mercado Común Latinoamericano. México.

- Chomsky, N. (2003). Towards a new Cold War. New York:The New Press .

- Cotler, J. y Fagen, R. (comp.) (1973). Relaciones políticas entre América Latina y Estados Unidos. Buenos Aires: Amorrortu.

- $\quad$ Cullather, N. (2006). Secret History: The CIA's classified account of its Operations in Guatemala, 1952-1954. California: Stanford University Press.

- Del Arenal, C. (1994). Introducción a las Relaciones Internacionales. Madrid: Tecnos.

- Delgado Ramos, G. (2010). "Seguridad Nacional e Internacional y Recursos Naturales. Tareas. No. 135. Panamá, mayo- septiembre.

- Delgado Ramos, G. (2010a). "América Latina y el Caribe como reservas estratégicas de minerales: dependencia y geopolítica estadounidense" en Delgado, Gian Carlo (coord.). Ecología Política de la Minería en América Latina. México: CEIICH-UNAM.

- Delgado Ramos, G. (2002) La amenaza biológica. México: Plaza y Janes.

- Delgado Ramos, G. y Romano, S. (2011). "Political-Economic Factors in US Foreign Policy. The Colombian Plan, the Merida Initiative and the Obama Administration". Latin American Perspectives. Vol. 38. No. 4. EUA: 93 - 108.

- Dell, S. (1984). "The emergente of UNCTAD" IDS Bulletin, vol 15 no 3, july. Institute of Development Studies, Essex, pp. 7-13.

- $\quad$ Di Tella, T. (1993). Historia de los partidos políticos en América Latina. Buenos Aires: FCE.

- Dos Santos, T. (1975). "La estructura de la dependencia" en Economía política del imperialismo. Buenos Aires: Ediciones Periferia, pp. 41-64.

- Dos Santos, T. (1972). Socialismo o fascismo. El nuevo carácter de la dependencia y el dilema latinoamericano. Buenos Aires: Ediciones Periferia.

- $\quad$ Dunne, T. y Schmidt, B. (2001). "Realism" en Baylis, John \& Smith, Steve The Globalization of world politics. An introduction to international relations. New York: Oxford 
- Fernandes, F. (2008). A revoluçao burguesa no Brasil. San Pablo: Globo

- Ferrer, A.(1976). Economía internacional contemporánea. Texto para latinoamericanos. México: Fondo de Cultura Económica.

- Gaddis, J.L. (2003) "Ideología, economía y solidaridad de alianzas". De Sur a Norte, vol. 5, núm. 5, Centro de Estudios Americanos, Buenos Aires, pp. 81-119.

- Gaddis, J.L. (1994) "The tragedy of Cold War history". Foreign Affairs, vol. 73, num. 1, enero-febrero, pp 142-154.

- Gaddis, J.L. (1989) Estados Unidos y los orígenes de la Guerra Fría. Buenos Aires: GEL.

- González Casanova, P. (1979). Imperialismo y liberación. Una introducción a la historia contemporánea de América Latina. México: Siglo XXI.

- Griffinth, R. y Baker, P. (eds.) (2001). Major problems in American history since 1945. Boston: Houghton Mifflin.

- Gunder Frank, A.(1970). "El desarrollo del subdesarrollo" en Guder Frank, Andre; Cockroft, James y Johnson, Dale, Economía política del subdesarrollo en América Latina. Buenos Aires: Signos, pp. 27-42.

- Gunder Frank A. (1965). Capitalismo y subdesarrollo en América Latina. Capítulo 1. C. "América Latina colonial y capitalista"

- http://www.eumed.net/cursecon/textos/Frank/index.htm

- Habermas, J. (1986). Ciencia y técnica como ideología. Madrid: Tecnos

- Hobden, S. \& Jones, R. (2001). "Marxist theories of international relations" in Baylis, John \& Smith, Steve The Globalization of world politics. An introduction to international relations. New York: Oxford, pp. 200-223.

- Hobsbawm, E. (1999). Historia del siglo XX. Buenos Aires: Grijalbo.

- Hoffmann, S.(1991). Una Ciencia Social Norteamericana: relaciones internacionales en Hoffmann, Stanley Jano y Minerva. Ensayos sobre la Guerra y la paz. Buenos Aires: GEL.

- Huberman, L.y Sweezy, O. (1973). Teoría de la política exterior Norteamericana. Buenos Aires: Merayo.

- Jonas, S. (1979). "La democracia que sucumbió. La revolución guatemalteca de 1944 a 1954" en Tobis, David y Jonas, Susane Guatemala, una historia inmediata. México: Siglo XXI, pp. 83-110.

- Johnson, D. (1970). "Dependencia, desnacionalización del desarrollo y sistema internacional" en Guder Frank, Andre; Cockroft, James y Johnson, Dale, Economía política del subdesarrollo en América Latina. Buenos Aires: Signos, pp. 93-192.

- Joseph, Gilbert M. (2008). "What we know now and should know: bringing Latin America more meaningfully into Cold War studies" en Joseph, Gilbert y Spenser, Daniela (eds.) In from the cold. Latin America's new encounter with the Cold War. Estados Unidos: Duke University Press.

- Joseph, G.(2004). "Lo que sabemos y lo que deberíamos saber: la nueva relevancia de América Latina en los estudios sobre la Guerra Fría" en Spenser, Daniela [coord]. Espejos de la Guerra Fría: México, América Central y el Caribe. México: CIESAS-Porrúa, pp..67-94.

- $\quad$ Kolko, G.(1968). The Politics of War. New York: Random House. 
- $\quad$ Lafeber, W. (1989). The American age: United States foreign policy at home and abroad since 1750. New York: Norton \& Company.

- $\quad$ Leffler, M. (1999). "The Cold War: What do 'we do know'?" American Historical Review, april, pp 501-524.

- $\quad$ Loveman, B. (ed.) (2006). Addicted to Failure. US Security Policy in Latin America and the Andean Region. Maryland: Rowman \& Littlefield

- Magdoff, H. (1975). "Militarismo e imperialismo" en Magdoff, Harry, Dos Santos Theotonio, Wolff, Richard y Sweezy, Paul Economía política del imperialismo Bs As: Ediciones Periferia.

- Marti, J. (1973). Cuba, Nuestra América y los Estados Unidos. México: Siglo XXI (111-149)

- Mecham, J. (1961). The United States and the Interamerican System 1889-1960. Texas: Austin University Press.

- Meiksins Wood, E. (2000). Democracia contra capitalismo: la renovación del materialismo histórico. México, Siglo XXI Editores.

- Melman, S. (1972). El capitalismo del Pentágono: la economía de guerra. México: Siglo XXI

- Morray Jean. P. (1970). "Estados Unidos y América Latina" en Petras, J. y Zeitlin, M. (Selecc.) América Latina: ireforma o revolución? Buenos Aires: Tiempo Contemporáneo, pp. 97-116.

- Myrdal, G. (1964). Teoría económica y regiones subdesarrolladas. México: Fondo de Cultura Económica.

- $\quad$ Perkins, D. (1964). Historia de la Doctrina Monroe. Buenos Aires: Eudeba.

- Pollard, R. (1990). La seguridad económica y los orígenes de la Guerra Fría 1945-1950. Buenos Aires: GEL

- Pozzi, P. (2003). "Estados Unidos y los orígenes de la Guerra Fría", De Sur a Norte, vol. 5, núm. 5, Centro de Estudios Americanos, Buenos Aires, pp. 13-21.

- Prebisch, R. (1949). El desarrollo económico de América Latina y algunos de sus principales Problemas. Santiago de Chile: CEPAL.

- $\quad$ Rabe, S. (1988). Eisenhower and Latin America. The Foreign Policy of Anticommunism. University of North Carolina Press.

- Romano, S. (2010) "Democracia liberal y seguridad en el Gobierno estadounidense: continuidades y rupturas" en Gandásegui, Marco y Castillo Fernández, Dídimo Estados Unidos: la crisis sistémica y las nuevas condiciones de legitimación. México: CLACSO-Siglo XXI, pp. 360-384.

- $\quad$ Romano, S. (2008). "La OEA y la política exterior norteamericana con respecto a América Latina en el marco de la Guerra Fría" Enfoque Social, no 4, México: Universidad de Tamaulipas, pp. 59-95.

- Salomón, M. (2001). "La teoría de las relaciones internacionales en los albores del siglo XXI, diálogo, disidencia, aproximaciones". Revista CIDOB d'Afers Internacionais, no 56, pp. 7-52.

- $\quad$ Saxe-Fernández, J. (1975). Proyecciones hemisféricas de la Pax Americana. Buenos Aires: Amorrortu. 
- $\quad$ Schlesinger, A.(1990). Los ciclos de la historia americana. Bs As: R.E.I.

- $\quad$ Schlesinger, S. y Kinzer, S. (1987). Fruta amarga. La CIA en Guatemala. México: Siglo XXI

- $\quad$ Singer, H. (1984). "Ideas and policy: the sources of UNCTAD" IDS Bulletin, vol 15 no 3, july. Institute of Development Studies, Essex, pp. 14-17.

- Sunkel, O. (1975). Capitalismo transnacional y desintegración nacional en América Latina. Buenos Aires: Nueva Visión.

- $\quad$ Sunkel, O. y Paz, P. (1980) El subdesarrollo latinoamericano y la teoría del desarrollo. México: Siglo XXI

- $\quad$ Sweezy, P. (1973). Capitalismo e imperialismo Norteamericano. Buenos Aires: Merayo

- $\quad$ Sweezy, P. y Magdoff, H. (1972). Dinámica del capitalismo norteamericano. La estructura monopolista, la inflación, el crédito, el oro y el dólar. México: Nuestro Tiempo.

- Tapia Valdés, J. (1980). El terrorismo de Estado. La doctrina de la seguridad nacional en el Cono Sur. México: Nueva Imagen.

- Veneroni, H. (1971). Estados Unidos y las fuerzas armadas de América Latina. Buenos Aires: Ediciones Periferia.

- Walsh, W. (1974) Introducción a la filosofía de la historia. México: Siglo XXI

- Wills, G. (2010). Bomb power. The modern presidency and the national security state. New York: Penguin Books.

- $\quad$ Zinn, H. (1999). La otra historia de los Estados Unidos (desde 1492 hasta hoy). México: Siglo XXI

\section{Documentos}

- United States Deparment of State, Foreign Relations, 1949, Vol I. Report by the Policy Planning Staff, p. 270

- United States Departement of State, 1950 US Policy regarding Hemisphere Defense, Vol $\mathrm{I}, 601,603,604,605,617,618,619,620,621,622,623,628,629,630,633,634,637,638$, $639,640,650,660,657-658$,

- United States Department of State, Foreign relations of the United States, 1951. The United Nations; the Western Hemisphere. Volume II, 952, 954, 955.

- $\quad$ United States Department of State, Guatemala, Vol II, 1951, 1439, 1442

- United States Department of Sate. Foreign Relations, Vol. IV, Foreign Assistance, International Development, Trade Policies 1970-1972 Doc. 148 Editorial Note

- $\quad$ Boletín del Departamento de Estado, 1949, La meta de Estados Unidos en el mundo del futuro, embajador Philp. C. Jessup, 243.

- Boletín del Departamento de Estado, 1949, El rol de Estados Unidos en el desarrollo económico en el extranjero, Wilfred Maelnbaum, Jefe de la Sividión de inversiones y desarrollo económico, 374.

- $\quad$ Boletín del Departamento de Estado, 1972, El Programa de Seguridad Mutua: un programa para la paz. Mensaje del presidente Truman al Congreso, 403-404.

- $\quad$ Boletín del Departamento de Estado, 1952, Ayudando a reforzar al Mundo Libre, 473. 
- Boletín Departamento de Estado, 1953, Inversión privada sobre bases asociativas, 310

- Boletín Departamento de Estado,1953, 464 Asistencia Militar a América Latina

- Boletín Departamento de Estado, 1953, Asistencia militar a América Latina. La amenaza comunista, 466-467

- Boletín Departamento de Estado, 1953, Manteniendo un comercio mutuamente ventajoso con América Latina. Eduard Cole, Director de la Oficina de Asuntos Regionales Americanos 716-718

- Boletín Departamento de Estado,1953, El valor de la cooperación técnica en América Latina, John Cabot Lodge, Subsecretario de Asuntos Interamericano, 780-781

- Boletín Departamento de Estado,1953 Inversión de capital estadounidense en Latinoamérica, 461-462.

- $\quad$ Boletín Departamento de Estado, 1953, Resumen de las actividades del EXIm Bank, 222

- Boletín Departamento de Estado,1953 371 Malebaum

- Boletín del Departamento de Estado, 1953, Los Estados Unidos y las áreas subdesarrolladas, Stanley Andress, Administración para la Cooperación técnica, 307-308 